\title{
The Teacher Leader in Context of Shared Leadership in Public Schools
}

\author{
Münevver Çetin ${ }^{1, *}$, Sıtar Keser ${ }^{2}$ \\ ${ }^{1}$ Marmara University, Atatürk Faculty of Education, İstanbul, Turkey \\ ${ }^{2}$ Teacher, Istanbul, Turkey \\ *Corresponding author: mcetin@marmara.edu.tr
}

Received July 10, 2015; Revised July 27, 2015; Accepted July 29, 2015

\begin{abstract}
In this research, the main purpose is that teachers put forward their views in the context of the responsibilities they incur in the presence of the existing change and conversion at schools, and assess these views within the teacher leader perspective in the context of shared leadership. Thus, in this research the responsibilities of teachers, what kind of a role they play in the context of change and conversion, their views about their position in the school organization and the sufficiency of this position are the points that are targeted to be found out. In this study, qualitative data collection design is used in accordance with the purpose of receiving the opinions of teachers regarding the teacher leader responsibilities in the context of shared leadership. The study group of this research consists of 30 teachers from various fields who work in public schools in the 2014-2015 academic year. The data acquired from the opinions of participant teachers are evaluated in the context of five different themes: (1) Student learning, (2) Career development, (3) Organizational change, (4) Environmental change and (5) Education policies. The analysis of the opinions of participants in the context of student learning reveals that the altruist approach that centers students in providing student learning and developing it is expressed more. The analysis of the participants' opinions in the context of career development reveals that this kind of efforts develop based on following periodicals, reading books, experience sharing and exchange of ideas.
\end{abstract}

Keywords: shared leadership, teacher leader, student learning and organizational change

Cite This Article: Münevver Çetin, and Sitar Keser, "The Teacher Leader in Context of Shared Leadership in Public Schools." American Journal of Educational Research, vol. 3, no. 8 (2015): 1027-1035. doi: 10.12691/education-3-8-13.

\section{Introduction}

The complex structure of our age deeply affects our whole life, and causes us to be exposed to different types of stimulants at different levels thousands of times in our daily routine. This diversifies our personal needs and also our expectations that come along based on these needs. Different expectations of different individuals become partners on the social ground and personal expectations turn into social demand. In our age in which sociability and individuality intertwine, the organizations that emerge with the claim to satisfy these expectations and that are fed sometimes with public funding and sometimes with private enterprise find the opportunity to survive as long as they sustain their claim to satisfy these expectations; the other organizations on the other hand disappear off the face of the earth due to the inability to be the answer for these expectations. At this point, the question 'what kind of an organizational structure can survive?' confronts us. In other words the question 'what kind of an organizational structure can be the answer for the expectations?' confronts us.

Because of the complex structure of the age, it is unlikely to expect the old hierarchical and vertical structuring of the old times to meet the social demands of the age. At this point, the organizational models of which the specific weight of every single element that is based on horizontal relationships shine out, and also the organizational models in which the power in total becomes important come to the forefront. The organizational models of which every member incurs responsibility and brings his/her personal expectations that make the existence of them important at formal and informal levels - in conformity with organizational goals come up with the claim of satisfying the social and individual expectations of the age. Within the scope of shared leadership styles, leadership is addressed in a collective context, every member of it has a perception based on this reality and team works turn into active elements of leadership, and therefore shared leadership styles make possible the organizational models that aim to meet the social expectations mentioned above.

The first and foremost place that the diversity of social demands is most intensely felt is the educational institutions. This diversity of social demands increases the number and diversity of individuals and communities that schools deal with. This diversity also increases and diversifies the responsibilities that every factor of educational institutions - primarily schools - assumes and has to assume. That is why the shared leadership models 
that develop in the context of collective leadership turn into important mechanisms for schools with regards to being the answer of expectations. The shared leadership applications that take shape in this sense go beyond the leadership spiral that is defined in the formal dimension and pave the way for turning every teacher into teacher leader on an informal basis which also includes the formal basis.

\subsection{Shared Leadership}

The most common problem in the group works of organizations is the 'how should the group leadership be?' problem. A versatile leadership style that is to reveal the competences and skills of every single group member at a maximum level and therefore increase the performance and efficiency of the group has become important. Creating an organizational climate in which all the members can transfer their skills, funds of knowledge and experiences to the extent that the organization needs them, in other words every single member is a "leader" to the extent that the organization needs that leadership will be important in making the group spirit functional [1].

A recent dispute is about the question 'which forms of management will be adequate in meeting the new needs that have come in sight?' and this dispute has started especially with the applications becoming prominent in which group spirit shines out. The question 'with which leadership can new circumstances like innovation be made sustainable?' has become one of the principal questions. At this point, one of the leadership forms having the ability to be the answer for this kind of questions is the "Shared Leadership" which is expected to contribute especially the innovation-based behaviors of organization members [6].

The analyses of studies regarding leadership reveal that the leadership forms that provide a basis for shared leadership are addressed on three bases [14]:

1. Distributed and dependent leadership; on this basis of leadership, a leadership structure is presented in which leadership applications and tasks are distributed to others at every level in an organizational context rather than hierarchical relationships based on a formal structure.

2. Leadership based on social interaction; leadership is a process which is created together by the leader and his/her followers. It is process that is based on dynamic, versatile and collective applications, and that develops in the context of common interests and goals between members.

3. Learned leadership; in this perspective, leadership is presented as a process that is based on the sharing between individuals and groups, in which leadership is learned and shaped together and that produces positive results. Leadership is a process that is shaped in the context of the development of every member's communication skills (transparency, trust, conflict management) and other skills (selfawareness, teaching strategies).

The leadership perspectives that take shape in this context are observed to focus on leadership styles like shared leadership, distributed leadership and cooperative leadership which do not highlight the individualism in which current leadership conceptualizations are inclusive of the leadership practice of the group members who have very different qualities in managing the group together [9].

These leadership styles are the styles that ground on mutual interaction rather than central and autocratic decision making processes, on that sense develop based on an interactive process, put forward a cooperative leadership and are collateral in a theoretical regard. Even though these leadership perspectives differ in certain ways, they resemble each other in emphasizing human affairs in organizational life and bringing a social perspective to organizational life [8].

The essential point of distributed leadership is the fact that more than one individual take responsibility at the point of leadership. The leadership responsibilities are divided between different individuals. In shared leadership on the other hand, leadership should be understood as a process that develops between peers and followers. It also does not lay down the fact as a condition that the shared leadership process of every individual gets involved in the process at the formal level [8]. In other words while distributed leadership come in sight based on the distribution of tasks and responsibilities - that take shape in a formal context -between individuals, shared leadership comes into the picture as a process that contains the sharing of leadership rather than dividing the leadership responsibilities which has an informal dimension as well.

Shared leadership is the sharing or distributing of activities in order to provide the functionality of the group. In this sense shared leadership can be described as a dynamic and interactive process in which group members mutually interact in achieving both the group's goals and the organization's goals. Therefore it is possible to indicate that the factor that separates shared leadership from the traditional leadership styles based on an individual is that it highlights a process based on interaction rather than the top-down influencing process of status-based leadership. In other words it grounds on horizontal relations. Leadership is divided between individuals rather than an individual who plays the leadership role (quoted from Pearce and Conger by NHS [11]). It is handled as a designed process that aims to achieve the goals of the group or organization which take shape based on the needs that emerge in a contingent context and the competences of its members, and grounds on the sharing of activities between members [2]. In this regard, shared leadership is an interactive leadership process based on mutual interaction in which every member influences another member in order to achieve predetermined goals [8].

As different descriptions in Table 1 suggest, there are some differences in the descriptions made in the context of shared leadership. However it is possible to observe similar descriptions because of the following facts; (1) focusing on leadership process, (2) the way of defining leadership, (3) the sharing or distributing of leadership, (4) dynamics of leadership process and (5) grounding on multiple roles and functions [3].

\subsection{The Teacher Leader}

It is possible to indicate that shared leadership has a strong impact on group behaviors, manners, cognition level and performance since it corresponds to a dynamic 
interactive process between group members [12]. Shared leadership indicates the powerful relationship between learning and teaching due to the fact that it highlights interaction [14]. Schools are the foremost institutions in which the most intense interaction between learning and teaching is experienced. In fact the existence of schools is built on this service. Schools are the organizations that learn more than all other organizations and they are places at which all the participants - teachers, students, managers and parents - can develop their creating and succeeding capacities all the time [7].

Table 1. Definitions of Shared Leadership by Theoretical Distinction

\begin{tabular}{|c|c|c|c|}
\hline Date & Authors & Definition Used & Theoretical Distinction \\
\hline 2002 & $\begin{array}{l}\text { Sivasubramanium, Murry, } \\
\text { Avolio, \& Jung }\end{array}$ & $\begin{array}{l}\text { Collective influence of members in a team on } \\
\text { each other; how members of a group evaluate } \\
\text { the influence of the group as opposed to one } \\
\text { individual within or external to the group }\end{array}$ & Aggregation \\
\hline 2006 & $\begin{array}{l}\text { Ensley, Hmieleski, \& } \\
\text { Pearce }\end{array}$ & $\begin{array}{l}\text { Team process where leadership is carried out by } \\
\text { the team as a whole rather than solely by a single } \\
\text { designated individual }\end{array}$ & Aggregation \\
\hline 2011 & Gupta, Huang, \& Yayla & $\begin{array}{l}\text { Team's capability for collectively engaging in } \\
\text { transformational leadership behaviors; leadership } \\
\text { as a collective process, such that the team } \\
\text { influences, inspires, and motivates team members }\end{array}$ & Aggregation \\
\hline 2002 & Erez, LePine, \& Elms & $\begin{array}{l}\text { Leadership can be shared over time whereby team } \\
\text { members share (albeit not at once) in responsibilities } \\
\text { involved in the leadership role ... by clarifying who } \\
\text { is to perform specific role behaviors (i.e., leader and } \\
\text { member) }\end{array}$ & Centralization \\
\hline 2006 & $\begin{array}{l}\text { Mehra, Smith, Dixon, \& } \\
\text { Robertson }\end{array}$ & $\begin{array}{l}\text { Shared, distributed phenomenon in which there can } \\
\text { be several (formally appointed and/or emergent) } \\
\text { leaders }\end{array}$ & Centralization \\
\hline 2009 & Mendez & $\begin{array}{l}\text { A dynamic property that is not owned by any } \\
\text { particular team member but flows among multiple } \\
\text { people and adapts to the characteristics of the } \\
\text { situation }\end{array}$ & Centralization \\
\hline 1998 & Gerstner & $\begin{array}{l}\text { Viewed as a network of dyadic working } \\
\text { relationships between work group members }\end{array}$ & Density \\
\hline 2007 & $\begin{array}{l}\text { Carson, Tesluk, \& } \\
\text { Marrone }\end{array}$ & $\begin{array}{l}\text { "An emergent team property that results from } \\
\text { the distribution of leadership influence across } \\
\text { multiple team members" }\end{array}$ & Density \\
\hline 2012 & Zhou & $\begin{array}{l}\text { The distribution of leadership influence across } \\
\text { multiple team members }\end{array}$ & Density \\
\hline
\end{tabular}

Source: [3].

At a traditional school, leadership reveals itself in a practice that is based on the periodical meetings of managers and the assistant managers about the procedural processes and things to do. The decisions made are conveyed to teachers as long as the decisions concern them. Executives of schools focus more on the processes about the entrance of resources. They are interested in subjects like whether textbooks have arrived or not, and which room or which classroom needs which equipment [16].

Nonetheless in a school where shared leadership is effective, all adults be a part of a process that grounds on learning together and continuously, and thus they help every student attain the optimal learning level that they are able to reach. The school executive plays the facilitator role. He/she guides the teachers in developing their effectiveness. For example he/she takes the initiative of the event in which teachers in every community or branch come together at certain intervals. He/she provides that teachers take initiative in structuring the processes of education. In other words every single teacher turns into a leader and contributes the co-creation of the leadership process [16].

Learning should be handled as a process in which all the school community gets involved rather than a process that is given place only in in-classroom activities. In other words schools should be places where decision processes are addressed in a free and open way in order to proactively answer possible changes, educational services are openly conducted and resources are allocated considering every student's needs. Within this perspective, schools which are expected to be an answer for modernday needs should have the following qualities [13]:

- An open vision that is supported with a cluster of values that is to guide the process of the shaping of the applications, processes and policies at school,

- A strong focus on student outputs that enrich the teaching and learning applications and at the same time the curriculum,

- Turning into an information-based and professional learning community that grounds on continuous development which provides personal development at a perfect level, 
- All stakeholders including teachers, families and also other members of the society playing an active role in developing a powerful cooperation in order to develop and carry a step further the existing potential,

- The existence of a school management that grounds on openness and transparency and takes the responsibility of ensuring accountability in order to guarantee that public funding is utilized appropriately.

It is inevitable to actualize an approach that necessitates every member of the school to play certain roles in creating the school qualities mentioned and making these qualities permanent, and this role-playing should be at the leadership level. The basis should be a school climate that grounds on continuous interaction in the context of shared leadership and therefore grounds on the fact that every member of the school gets involved in the learning process and develop their competence. At this point the concept of teacher leader comes in sight.

Three primary factors, which will enable shared leadership to be invigorated at school where the teacher turns into a leader, should be provided to be clear (quoted from Spillane by Lindahl [10]): (1) distribution of work, (2) joint effort and (3) parallel effort. These factors draw the frame of who undertakes what, what should be the necessary joint performance of community or department teachers and the working process that goes parallel with other communities, departments and the management. In other words, ensuring the school community turning into an integrated structure is emphasized. In this regard it is expected that shared leadership is made functional, in other words the school preserves its qualities and thus keeps pace with the changing process and the teachers who are called the teacher leaders play various roles.

Teachers can contribute the planning stage by providing feedbacks regarding the applications of learning and teaching processes since they are the first hand implementers and followers of these applications. The teacher leaders fulfill their key roles in achieving the targets and the vision of the school with their competences at the expertise level. The teacher leader roles reveal themselves in a quite wide range from contributing the curriculum, being an authority in the meaning of expertise and being a member of school development teams to being a mentor to colleagues who have less experience or who need a mentor, being active researchers and more importantly establishing very strong bonds with the classroom [5].

The teacher leaders can set an example for all their friends and the whole school community, they can play an active role in the monitoring and evaluation processes and they can contribute the planning stage of various applications before they are implemented. There are teacher leader roles that are put forward by different researchers as shown by Table 2 apart from the possible contributions mentioned above originating from teachers in the context of shared leadership [10].

Table 2. Expectations from Teacher Leaders in the Context of Shared Leadership

\begin{tabular}{|c|c|c|}
\hline Date & Writer & Expected from the Teacher leader \\
\hline 1987 & Daveney & $\begin{array}{ll}- & \text { Continues to teach and improve his/her own teaching } \\
\text { - } & \text { Organizes and leads well-informed peer reviews of school practice } \\
\text { - } & \text { Participates productively in school-level decision making } \\
\text { - } & \text { Organizes and leads in-service education that is meaningful to the student population and school program } \\
\text { - } & \text { Advises and assists individual teachers through mentoring, coaching, or consultation } \\
& \text { Participates in the performance evaluation of teachers by providing appropriate appraisal and feedback }\end{array}$ \\
\hline 1999 & Bergmann et.al. & $\begin{array}{ll} & \text { Creates a compelling future } \\
- & \text { Lets the customer drive the organization } \\
- & \text { Involves every mind } \\
\text { Manages work horizontally } \\
\text { Builds personal credibility }\end{array}$ \\
\hline 2002 & Crowther et.al. & $\begin{array}{ll} & \text { Conveys convictions about a better world } \\
- & \text { Strives for authenticity in his/her teaching, learning, and assessment practices } \\
- & \text { Facilitates communities of learning through organization-wide practices } \\
- & \text { Confronts barriers in the school’s culture and structures } \\
\text { - } & \text { Translates ideas into sustainable systems of action } \\
& \text { Nurtures a culture of success }\end{array}$ \\
\hline 2006 & Beach & $\begin{array}{ll}\text { The teacher leader incurs responsibilities in the following: } \\
\text { - } & \text { Assessment } \\
\text { - } & \text { Culture } \\
\text { - } & \text { Vision } \\
\text { - } & \text { Plans } \\
\text { - } & \text { Implementation } \\
\end{array}$ \\
\hline
\end{tabular}

Harris [5] handled the teacher leader roles in four dimensions with different aspects, and these roles have been presented from different perspectives: (1) brokering (2) participative (3) mediating and (4) collaborative roles [5].

1. Brokering role: This dimension is about the teacher's role of being able to transfer the developments that emerge in the context of education to in-classroom implementations. This role contains an emphasis to the responsibility of the teacher in the creation of opportunities of making the maximum use of developments that are to contribute in a school context.

2. Participative role: The second dimension emphasizes the teacher leader role in the con-text of the conversion of every single teacher into a factor of the leadership process with reference to the awareness that every teacher is a part of change and conversion. The teacher leaders help the other colleagues of them on the grounds of possible develop-ments, and they support the implementations that strengthen 
collaboration. They guide the process of making a joint effort within common goals.

3. Mediating role: The third dimension emphasizes the mediating role of the teacher leader in the enhancing of the school. Teacher leaders are experts in their field and they are one of the most important sources of information at this point. The expertise of outside sources should also be utilized whenever needed.

4. Collaborative role: This dimension contains the roles regarding the development of close relationships between teachers and getting involved in the learning processes that will together and mutually contribute both the personal and professional development based on these relationships.

The school leadership of which teachers are also a part is not effective only in the area bordered by school walls. The school leaders who play roles based on shared leadership also play roles in establishing relationships and developing this collaboration with other schools and communities that surround the school. They share resources and create working opportunities together based on the roles they play in order to strengthen the collaboration. At the same time they contribute the development of a culture that will be influential in producing a social benefit based on responsibility by increasing the role of the school [15].

Ultimately the teacher leadership takes shape at the point of fulfilling the needs of the following three factors: (1) student, (2) school and (3) teaching profession [4]. It produces social benefit in proportion to the contribution of it to these three factors. Its contribution regarding this social benefit necessitates taking various roles in quite different fields. A great variety of teacher leader responsibilities can be gathered under the following fields [4]:

Domain 1 - Creating and developing a collaborative culture that feeds the learning of students and professional development: The teacher leader knows what the learning principles are. He/she contributes the development of a collaborative culture at school based on joint responsibility. Teacher leaders do not abstain from sharing their fund of knowledge with their colleagues on the basis of trust and respect in order to enhance student learning.

Domain 2 - Making research in order to develop implementations of education and student learning and using the research results: Teacher leaders know the ways to reach new information, transfer what they achieve to implementation and develop the teaching and learning processes. It all turns into a continuous learning and teaching process.

Domain 3 - Continuing professional learning for continuous development: The teacher leaders are aware of the teaching and learning processes, the existing and new technologies and the development and change in the nature of school community. He/she uses the funds of knowledge that constitute the base for this awareness in designing, maintaining and facilitating the professional learning that centers the school development. In this regard, the teacher leader fulfills the following responsibilities:

Domain 4 - Facilitating education and learning processes: The teacher leader has deep knowledge in the context of teaching and learning processes. He/she uses this fund of knowledge in the development of learning competences of his/her colleagues. As a constant learner, he/she turns into a model in the development of students and reveals this with his/her implementations. He/she works collaboratively with his/her colleagues in the context of shared vision, mission and goals.

Domain 5 - Gathering information to contribute the development of the school and the school environment, using the evaluation data acquired as a result of this information and making this process periodical: The teacher leaders are informed about current classroom and school-based researches and they have the competency of developing and choosing the appropriate assessment methods. They share all their information with their colleagues in order to enrich the learning processes of students and develop collaboration with their colleagues. They make an effort to contribute the development of the school and its environment.

Domain 6 - Collaborating with families and other communities and developing this process: The teacher leaders are aware of the important impact of families, communities and different cultures on educational process and student learning. They work with colleagues, families, business leaders, community leaders and other stakeholders to make a systematic collaboration permanent in order to contribute the development of the system of education and create opportunities in the context of student learning.

Domain 7 - Defending and supporting student learning and teaching profession: The teacher leader is aware of the effect levels and who the school executives, lawmakers and other stakeholders are to have an impact on the formulation of educational policies the local and national levels. He/she uses his/her fund of knowledge in developing teaching processes and raising student learning level on a basis that considers student needs. As a member of this school community, he/she reveals his/her fund of knowledge in educational and professional implementations.

In this research, the main purpose is that teachers put forward their views in the context of the responsibilities they incur in the presence of the existing change and conversion at schools, and assess these views within the teacher leader perspective in the context of shared leadership that falls into the platform of collective leadership. Thus, in this research it is targeted to find out what the responsibilities of teachers are what kind of a role they play in the context of change and conversion, their views about their position in the school organization and the sufficiency of this position.

\section{Methodology}

In this study, qualitative data collection design is used in accordance with the purpose of receiving the opinions of teachers regarding the teacher leader responsibilities in the context of shared leadership.

\subsection{The Study Group}

The study group of this research consists of 30 teachers from various fields who work in public schools in the 2014-2015 academic year. In the sense of demographic features, the participants are as follows: 


\begin{tabular}{|l|l|l|l|l|l|l|l|l|l|}
\hline Participant & Age & Gender & Field & Seniority & Participant & Age & Gender & Field & Seniority \\
\hline P 1 & 28 & Female & Physical Education & 3 & P 16 & 33 & Female & Classroom Teaching & 10 \\
\hline P 2 & 33 & Female & Social Studies & 8 & P 17 & 30 & Male & Classroom Teaching & 9 \\
\hline P 3 & 30 & Female & Turkish & 6 & P 18 & 31 & Male & Classroom Teaching & 9 \\
\hline P 4 & 27 & Male & English & 4 & P 19 & 36 & Female & Classroom Teaching & 15 \\
\hline P 5 & 22 & Female & Science & 5 & P 20 & 29 & Female & Classroom Teaching & 7 \\
\hline P 6 & 35 & Female & Social Studies & 10 & P 21 & 31 & Female & Classroom Teaching & 10 \\
\hline P 7 & 41 & Male & Visual Arts & 15 & P 22 & 38 & Female & Classroom Teaching & 13 \\
\hline P 8 & 24 & Female & Science & 8 & P 23 & 38 & Male & Classroom Teaching & 13 \\
\hline P 9 & 28 & Male & Classroom Teaching & 5 & P 24 & 28 & Female & Classroom Teaching & 6 \\
\hline P 10 & 32 & Male & Classroom Teaching & 8 & P 25 & 32 & Male & Classroom Teaching & 7 \\
\hline P 11 & 29 & Male & Classroom Teaching & 6 & P 26 & 29 & Female & Classroom Teaching & 5 \\
\hline P 12 & 30 & Male & Classroom Teaching & 7 & P 27 & 29 & Male & Classroom Teaching & 5 \\
\hline P 13 & 28 & Female & Classroom Teaching & 5 & P 28 & 37 & Male & Classroom Teaching & 13 \\
\hline P 14 & 28 & Female & Classroom Teaching & 4 & P 29 & 27 & Female & Math & 3 \\
\hline P 15 & 29 & Male & Classroom Teaching & 5 & P 30 & 32 & Female & Preschool Education & 8 \\
\hline
\end{tabular}

\subsection{Data Collection Method}

Individual interview is used as the data collection tool. The opinions of teachers are taken by having face-to-face interviews. An interview form is prepared in order to describe the opinions of teachers regarding the teacher leader responsibilities.

\subsection{Analysis of the Data}

All the recorded interviews are transferred into the written form. Content analysis is utilized in the research in order to resolve the data acquired by the interview and for that purpose NVIVO 10 program is used. The answers given to questions are analyzed by the researcher and the codes that emerge as a result of these analyses are interpreted in the Findings and Discussion part in the context of themes.

\section{Findings}

The data acquired from the statements of the participants whose opinions regarding the teacher leader roles in the context of shared leadership are asked are analyzed under the following themes: (1) Student learning, (2) career development, (3) organizational change, (4) environmental change and (5) educational policies.

1. Teacher Opinions in the Context of Student Learning

Table 3. The Analysis of Teacher Opinions in the Context of Student Learning

\begin{tabular}{|l|l|l|l|l|}
\hline Theme & Code & Participant & $\mathrm{f}$ & $\%$ \\
\hline \multirow{5}{*}{ Student Learning } & Learning by Experience, & P 1, P 6, P 28, P 30 & 4 & 13 \\
\cline { 2 - 5 } & Altruist Approach, Student-Centered & P 2, P4, P5, P 16, P 18, P 20, P 21, P 22, P 23, P 25, P 26, P 27, P 29 & 13 & 43 \\
\cline { 2 - 5 } & Technological Support & P 3, P 17 & 2 & 7 \\
\cline { 2 - 5 } & Self-Discipline, Self-Confidence & P 7, P 8, P 10, P 14 & 4 & 13 \\
\cline { 2 - 5 } & Providing Feedbacks/Reward Punishment & P 12, P 13, P 15, P 24 & 4 & 13 \\
\cline { 2 - 5 } & Teamwork / Collaborative Learning & P 9, P 19, & 7 & 2 \\
\cline { 2 - 5 } & Time Planning & P 11 & 3 & 1 \\
\hline
\end{tabular}

The analysis of the participants' opinions regarding student learning reveals that the participants show different approaches. However it is expressed that altruist approaches are more frequently adopted which centers the student in ensuring student learning. Apart from that, providing self-discipline and using reward-punishment methods are also factors that are frequently expressed:

"I pay attention to the fact that the technique I will choose definitely coincides with the readiness level of the student and fits the competence and ability of the student. I mostly choose individual-based ways of learning. I think that every student has different kind of intelligence and therefore I try to perform education in accordance with the student's own interests and skills (P 26)”.

"First of all, the student has to gain acceptance by his/her teacher unconditionally. When the student knows that he/she is liked, he/she has more selfconfidence. As a teacher, I think the first thing that should be done as teachers is to like our students and make them feel this. The student exploring knowledge and being active in lectures facilitate learning. Teachers have to assign tasks to students in in-classroom activities (P 14)".

2. Teacher Opinions in the Context of Career Development 
Table 4. The Analysis of Teacher Opinions in the Context of Career Development

\begin{tabular}{|c|c|c|c|c|}
\hline Theme & Code & Participant & $\mathrm{f}$ & $\%$ \\
\hline \multirow{5}{*}{ Career Development } & Following periodicals, reading books & P 1, P 10, P 14, P 15, P 17, P 22, P 26, P 28, P 30 & 9 & 30 \\
\hline & Exchange of ideas & P 2, P 5, P 7, P 8, P 11, P 19, P 21, P 27 & 8 & 27 \\
\hline & Transferring experiences & P 3, P 4, P 16, P 18, P 24 & 5 & 17 \\
\hline & In-service training & P 6, P 9, P 20, P 25 & 4 & 13 \\
\hline & Using technology & P 12, P 13, P 23, P 30 & 4 & 13 \\
\hline
\end{tabular}

The participants whose opinions are taken expressed that they develop a dialogue with their colleagues generally with the intent of transferring experiences and exchanging ideas. Apart from that, they put into words the options of following periodicals and in-service training as well:

"Certainly, participation to meetings like seminars which is to contribute teacher development has to be encouraged in the first place. Teachers will participate if there is encouragement, otherwise there will be limited participation. In these meetings, for example the exchange of ideas even in a county group meeting allows us to make a situation assessment (P 9)".

"In order to be able to be a qualified teacher, I get information about students' development and readiness. I also improve myself in the following subjects: 'which methods and techniques I have to use for which students, and how the development features of students should be considered in the learning-teaching processes'. For these purposes, I constantly make researches and read therefore I renew myself" (P 15).

\section{Teacher Opinions in the Context of Organizational} Change

Table 5. The Analysis of Teacher Opinions in the Context of Organizational Change

\begin{tabular}{|c|c|c|c|c|}
\hline Theme & Code & Participant & $\mathrm{f}$ & $\%$ \\
\hline \multirow{8}{*}{ Organizational Change } & Problem solving & P 1, P 7, P 8, P12, P 30 & 5 & 17 \\
\hline & Being constructive & P 2, P 4, P 14, P 18 & 4 & 13 \\
\hline & Playing a role & P 3, P 23, P 26 & 3 & 10 \\
\hline & Being a role model & P 6, P 9, & 2 & 7 \\
\hline & Reaching agreement & P 5, P 15 & 2 & 7 \\
\hline & Contribution as ideas & P 16, P 17, P 19, P 21, P 22, Р 25, P 27, Р 29 & 8 & 27 \\
\hline & Teamwork & P 10, & 1 & 3 \\
\hline & Neutral & P 11, P 13, P 20, P 24, P 28 & 5 & 17 \\
\hline
\end{tabular}

Teachers' opinions were taken in the participation to decision-making processes, problem solving and conflict management in the context of organizational change, and they expressed that they mostly contribute in terms of ideas. They also stated that they stay out of processes and at that point they are ineffective:

"I can play roles that fall into my job description in solving problems of the school. It is not possible that we take part in administrative issues. I certainly express my ideas in cases like school executives using communication methods while managing the school. I think this is the right thing to do (P 17)".

"I prefer to remain silent in cases of conflict. I don't think that I have much effect on decision processes. I try to solve the problems of the school on my own and within my power. As much as I can solve... (P 20).

\section{Teacher Opinions in the Context of Environmental} Development and Stakeholder Relations

Table 6. The Analysis of Teacher Opinions in the Context of Environmental Development and Stakeholder Relations

\begin{tabular}{|l|l|l|l|}
\hline Theme & Code & Participant \\
\hline \multirow{4}{*}{$\begin{array}{l}\text { Environmental Change } \\
\text { with Stakeholders }\end{array}$} & Being a role model & P 1, P 2, , P 10, P 12, P 17, P 25, P 26 \\
\cline { 2 - 4 } & Problem solving & P 3, P 27 & 7 23 \\
\cline { 2 - 4 } & Creating activity fields & P 4, P 9, P 14, P 15, P 16, P 19, P 23, P 28 \\
\cline { 2 - 4 } & Making effective in decision processes & P 5, P 29, P 30 & 8 27 \\
\cline { 2 - 4 } & Collaboration & P 6, P 7, P 8, P 11, P 13, P 18, P 20, P 22, P 24 & 10 9 30 \\
\hline
\end{tabular}

The participants whose opinions are taken in the context of contribution to environmental change and communication with stakeholders put forth their opinions at these points: 'being a role model with their behaviors, creating activity fields like theater, seminars, etc. and collaborating in every respect'.

"The teacher should not be a person who is not only taken as an example by a school but the whole society. $\mathrm{He} /$ she should set an example for everybody with his/her behaviors, patience and also with his/her unconditional love for his/her students. He/she should set an example so that the generations he/she raises contribute first to their environment and then to the development of their country as positive youngsters ( $\mathrm{P}$ 25)".

"The teacher should increase the collaboration with families for the development of the school and its environment. In this way, we have more contribution to the development of the education of the school apart from its visual development. If I wanted to develop my school, the greatest amount of money I would spend on would be the library and so it would be the most 
beautiful part of the school. I would try to make a big, perfect library by using all the resources even if the school itself was dilapidated. By doing that, I would produce a project that the students would come and study with pleasure and therefore that would be a project that would not develop the school from outside but from inside. Naturally, the students raised from that school would contribute the development of the school the most (P 6)".

\section{Teacher Opinions in the Context of Education Policies}

Table 7. The Analysis of Teacher Opinions in the Context of Education Policies

\begin{tabular}{|l|l|l|l|}
\hline Theme & Code & Participant & $\mathrm{f}$ \\
\hline \multirow{5}{*}{ Education Policies } & Neutral & P 1, P 7, P 8, P 12, P 13, P 16, P 19, P 20, P 21, P 23, P 25, P 28, P 30 \\
\cline { 2 - 4 } & Expressing opinion & P 2, P 10, P 14, P 24 & 13 \\
\cline { 2 - 4 } & Process monitoring & P 3, P 5, P 29 & 13 \\
\cline { 2 - 4 } & Playing a role & P 4, P 6, P 9, P 27 & 10 \\
\cline { 2 - 4 } & Guiding & P 11, P 15, P 17, P 18, P 22, P 26 \\
\hline
\end{tabular}

The participants - whose opinions are received in the context of the roles played in determining the education policies and implementing them - generally stated that they do not have an effect at this point. Apart from that, they presented the view that they play the role of pioneering the contributions and implementations at the intellectual level:

"The teacher has a role in which he/she contributes the development of students, sets an example for them, he/she is a leader, he/she has high level of knowledge in his/her profession, he/she motivates the students and builds the future by knowing the power of his/her profession (P 15)".

"What kind of a role should the teacher play in the changes that have been taking place in the field of education? In this system at the present time, our role is to pretend to be a teacher. The teacher is not a teacher anymore; he/she is a puppet. I think the teacher has lost his/her old prestige and value. Even a five-year-old kid says 'he/she is only a teacher'. It is not possible that we play a part in the recent changes because some people build things then bring them down and please themselves. I think the decisions and suggestions of outsiders - who are not in education - cannot improve education; on the contrary they create chaos (P 19)".

"The teacher should follow and research changes. After he/she comprehends and internalizes the logic of this change, he/she should develop approaches in order to realize the purpose. The implementer of this change is the teacher. However in order for the teacher to be able to internalize these changes, these changes - to a certain extent - should be accordant with the teacher's logic (P 27)”.

\section{Conclusion and Discussion}

The data acquired from the opinions of participant teachers are evaluated in the context of five different themes: (1) Student learning, (2) Career development, (3) Organizational change, (4) Environmental change and (5) Education policies. The data acquired from opinions in the context of these themes based on shared leadership are analyzed.

The analysis of the opinions of participants in the context of student learning reveals that the altruist approach that centers students in providing student learning and developing it is expressed more. Apart from that, efforts providing learning through experience, reward-punishment and creating self-discipline are other approaches that are stated in providing student learning. The findings reveal that there is more emphasis on individual efforts. The efforts that are in the direction of developing collaborative methods that ground on doing teamwork with colleagues in the context of student learning were not put into words. Apart from that, ETS [4] presented the view that one of the teacher leader responsibilities in the context of student learning should be in the direction of creating a school culture that supports collaboration. The analysis of the opinions reveals that the efforts for student learning are limited to in-classroom activities.

The analysis of the participants' opinions in the context of career development reveals that this kind of efforts develop based on following periodicals, reading books, experience sharing and exchange of ideas. These data can be assessed parallel to idea and experience sharing, basic participation and collaboration roles which are the trivets of teacher leadership introduced by Harris and Mujis [5]. Nonetheless, when the approach that is presented based on designing, sharing with others and continuing learning in the context of career development is used as base, it is possible to state that the participants are contented with more daily efforts and they do not develop a strategic approach in professional learning.

The opinions expressed in the sense of career development also coincide with role playing factors of contribution with ideas, problem solving and being constructive that are expressed at the point of contribution to organizational change. The other clearly expressed view in contributing organizational change is the one that can be explained as 'not contributing organizational change or remaining passive in organizational change processes', in other words 'being inactive'. Considering the positive relationship between shared leadership, teamwork and innovativeness in the research made by Hoch [6], this finding can be interpreted as the participants playing a limited role as a teacher leader in being the dynamics of organizational change.

It is possible to observe that the participants - whose opinions are asked in the context of contribution to environmental change and relationships with stakeholders - expressed these factors: setting an example with behaviors, creating fields of activity like theater or exhibition, collaborating in problem solving and including stakeholders to decision-making processes. The criterion of setting an example for the whole school community that Lindahl [10] stated and being a role model with 
behaviors which is expressed in teacher opinions coincide with each other in the context of teacher leadership. It is possible to observe that the efforts made are limited to individual sacrifice rather than a systematic approach. Therefore it is not possible to indicate that this case exactly meets the criterion that is explained by the argument of providing a systematic contribution to the development of the school and its environment which was presented by ETS [4].

Harris and Mujis [5] presented the teacher leadership roles as being consultants in contributing the curriculum and being experts in generating education policies. Apart from that, Schleicher [15] explained the role of the teacher leader as contributing by increasing the role of the school in developing a culture that will be effective in producing social benefit based on responsibility. In addition, ETS [4] explains the teacher leader as the individual who takes an active part in education policies and at this point contributes the development of the system of education. In the light of these assessments, the roles of the participants are asked and the expressions of the vast majority point that they do not play a role. Apart from that, the expressions become prominent in which they play the roles of watching the process and implementing the results. In this sense, it is possible to state that the participants who express that they do not have an effect on determining education policies based on teacher leadership do not play any part as teacher leaders.

In order for the shared leadership which shines out with its informal participation dimension and the teacher leadership which is the reflection of shared leadership in education to make sense practically, the existence of the following factors is necessary: (1) the existence of a set of values that will support the practice of teacher leadership, (2) a vision that has a guidance role in shaping and implementing education policies and also encourages active participation, (3) a systematic network of communication in which teachers and families play an active role, that includes the other members of the society and that will provide all the stakeholders develop a powerful collaboration, (4) an administration that includes local dynamics to decision processes while stretching the understanding of centralized administration and (5) a transparent structure that ensures the maximum usage of all kinds of resources in actualizing education targets.

\section{References}

[1] Bergman, J. Z., Rentsch, J. R., Small, E. E., \& Davenport, S. W. (2012). The Shared Leadership Process. The Journal of Social Psychology, 152 (1), 17-42.

[2] Buckmaster, S. (2004). Shared Leadership: What is it, why is it important, and who wants it. http://www.futureworksconsulting.com/resources/ka9shared.pdf. adresinden alınmıștır

[3] D’Innocenzo, L., Mathieu, J. E., \& Kukenberger, M. R. (2014). A Meta-Analysis of Different Forms of Shared Leadership-Team Performance Relations. Journal of Management , 20 (10), 1-28.

[4] ETS. (2011). Teacher Leader Model Standarts. https://www.ets.org/s/education_topics/teaching_quality/pdf/teach er_leader_model_standards.pdf. (Retrieved September 18, 2014).

[5] Harris, A., \& Mujis, D. (2003). Teacher Leadership: principles and practice. NCSL.

[6] Hoch, J. E. (2013). Shared Leadership and Innovation: The Role of Vertical. J Bus Psychol , 28, 159-174.

[7] Hoy, W. K. \& Miskel, C. K. (2010). Eğitim Yönetimi Teori Araşıırma ve Uygulama. Nobel Yayınları: Ankara.

[8] Jing, W. (2009). School Leadershıp In Two Countries: Shared Leadershıp In Amerıcan And Chınese Hıgh Schools. ProQust.

[9] Kramer, M. W. (2006). Shared Leadership in a Community Theater Group: Filling the Leadership. Journal of Applied Communication Research, 34 (2), 141-162.

[10] Lindahl, R. (2008). Shared Leadership: Can It Work in Schools? The Educational Forum , 72 (4), 298-307.

[11] NHS. (2014). Shared Leadership. Academy of Medical Royal Collages, 1-24.

[12] Pearce, C. L., \& Ensley, M. D. (2004). A Reciprocal and Longitudinal Investigation of the Innovation Process: The Central Role of Shared Vision in Product and Process Innovation Teams. Journal of Organizational Behavior, 25 (2), 259-278.

[13] Pang, Yui Kai (2000). Transforming Schools into Dynamic and Accountable Professional Learning Communities. Advisory Committee on School-based Management.

[14] Printy, S. M., \& Marks, H. M. (2006). Shared Leadership for Teacher and Student Learning. Theory into Practice, 45 (2), 125132.

[15] Schleicher, A. (2012). Preparing Teachers and Developing School Leaders for The 21st Century. OECD Publishing.

[16] Wilhelm, T. (2013). How Principals Cultivate Shared Leadership. Educational Leadership, 62-66. 